Tamara Britka

Universiteit van Belgrado

https://doi.org/10.18485/bgd_nlistiek_30.2018.ch2

\title{
HET BEELD VAN NEDERLAND EN DE NEDERLANDERS IN HET REISVERHAAL HOE KAN JE DE ZON KOPEN?
}

\begin{abstract}
This paper will aim to show how the theory of representation, as expounded by Maaike Meijer in her book Caught in the text. Introduction to the Criticsm of Representation (1996), can provide a good starting point for the interpretation of the travalogue by the Serbian writer Tihomir NešićHow could you buy the Sun?(1992). By introducing the concept of "cultural texts", Meijer pleads that the existing social and cultural narratives determine the formation of different mental images and impressions about reality. In his texts Nešić mainly confirms the positive stereotypical images regarding the Netherlands and the Dutch, while also shedding light on the certain, lesser known traits of the Dutch mentality. However, even by choosing to depict certain striking behavioural patterns, this paper argues that Nešić only succeeds to partially undermine some of the stereotypes typically related to the Dutch identity. Therefore, in this paper, Meijer's theory of representation shall be primarily used to explain how stereotypes regarding other countries and nations are formed and represented in works of literature.
\end{abstract}

Keywords: representation, cultural text, stereotype, stereotypical image, the other, identity, nation

\section{Inleiding}

Op reis gaan betekent zowel in contact komen met andere culturen als inzicht krijgen in het specifiek cultuur-historische erfgoed van de bezochte gebieden. Reisverhalen alsook andere literaire genres, met de focus op vreemde culturele achtergronden, geven altijd bepaalde beelden of visies weer van auteurs die dan tevens als bemiddelaars fungeren bij de beeldvorming over andere culturen. De term "visie" wordt in deze bijdrage gebruikt in de zin van representatie en daar wordt elke uiting of voorstelling in taal of beeld mee bedoeld in de betekenis die Maaike Meijer aan dit begrip toekent in haar werk In tekst gevat.Inleiding tot een kritiek van representatie (1996). Zij beschouwt representatie als "alle in taal of beeld gevatte uitingen" die zowel werkelijkheidsvormend zijn als bepalend voor de manier waarop de lezer bij de tekst wordt betrokken (Meijer 1996: 9). Volgens haar impliceert representatie "een bemiddelende activiteit: er is altijd 
iemand die de tekst, het beeld, de gedachte heeft gevormd" (Meijer 1996: 14). ${ }^{1}$

De gangbare mening is dat elke beeldvorming werkelijkheid afbeeldt. Meijer gaat daarentegen ervan uit dat beeldvorming zelf een werkelijkheid schept, dat wil zeggen dat "de werkelijkheid wordt vormgegeven en niet wordt weerspiegeld" door de gecreëerde beelden (Meijer 1999: 25). De beelden die in het proces van beeldvorming tot stand komen stellen representaties voor. Elke representatie is namelijk doortrokken van heersende waardeoordelen en machtsverhoudingen aan de hand waarvan een bepaalde ideologie weergegeven wordt. ${ }^{2}$ Van Alphen gebruikt het begrip "verstarde code" om de ideologische betekenisgeving van de lezer aan te duiden die tijdens het leesproces tot stand komt indien die code als vanzelfsprekend wordt ervaren. De code stelt de regel voor op basis waarvan een teken met betekenis wordt verbonden en indien een code al eindeloos herhaald is, wordt hij automatisch en eenzijdig in werking gezet bij elk leesproces. Meijer breidt de werking van dit begrip uit en introduceert de term "cultuurtekst" om er een cultureel model mee te bepalen dat in afzonderlijke teksten/beelden telkens wordt herhaald en dat zo verankerd is dat het niet meer als een cultuurtekst herkend kan worden (Meijer 1996: 15). Literaire teksten dragen altijd cultuurteksten in zich en ten opzichte van die cultuurteksten verhouden ze zich ondersteunend en construerend of ze kunnen tegen de verstarde ideologische mechanismen indruisen en op die manier een mogelijkheid scheppen om cultuurteksten te deconstrueren en te herschrijven.

Deze bijdrage is een poging om aan te tonen in hoeverre de beschrijvingen en voorstellingen over Nederlanders, hun nationale identiteit en cultuur, die in het reisverhaal van Tihomir Nešić Hoe kan je de zon kopen? (1992) worden weergegeven, als objectief beschouwd kunnen worden en in hoeverre ze representaties zijn van bepaalde ideologische beschouwingen van de auteur. De vraag is ook of de beeldvorming over Nederland in dit werk bepaalde stereotypes over dat gebied enigszins bevestigt of juist ondermijnt.

\section{De Nederlandse identiteit}

Er bestaan veel definities van het begrip identiteit waardoor het moeilijk wordt dat begrip op een eenduidige wijze vast te leggen. Identiteit kan omschreven worden als de manier waarop een persoon in relatie met een bepaalde omgeving wordt gedefinieerd en zichzelf definieert. Aangezien identiteit een meerduidig begrip is kan hij zich ook manifesteren als iets collectiefs. Mensen zien zichzelf en worden gezien als lid van een bepaalde groep, zoals bij een nationale of religieuze identiteit (www 2).

1 Dit kenmerk onderscheidt representatie van het semiotische begrip 'teken', bij de schepping waarvan geen sprake hoeft te zijn van bemiddelende menselijke activiteit. "Alles kan een teken zijn, vatbaar voor betekenisgeving, maar niet alles is een representatie"(Meijer 1996:14).

2 Over de verhouding tussen representatie en werkelijkheid zie meer in: M. Meijer In tekst gevat. Inleiding tot een kritiek van representatie, p.15-17 
Een nationale identiteit kan beschouwd worden als een culturele identiteit met unieke tradities, waarden en normen.De kenmerken op grond waarvan deze categorieën tot stand komen, worden sociaal toegekend en gedefinieerd. Bepaaldeidentiteitskenmerken en categorieën worden al van kinds af aan via processen van enculturatie en socialisatie aangeleerd binnen een bepaalde groep. Naast groepsidentiteiten kan identiteit als iets individueels gezien worden, zoals bij de persoonlijke identiteit. Toch wordt identiteit beschouwd als een sociale constructie die niet tot stand kan komen en niet kan bestaan zonder anderen (www 1).

Een Nederlandse historicus, Maarten van Rossem, heeft getracht een beeld te schetsen van de Nederlandse nationale identiteit door verscheidene sociaalhistorische onderzoeken uit te voeren. Volgens de uitslagen zou de 'typische' Nederlander nuchter zijn, zelfverzekerd, verstandig, kritisch en eerlijk. Maar een Nederlander zou ook bijvoorbeeld baldadig zijn. Van Rossem baseert zijn gegevens op de stereotype voorstellingen die buitenlanders door de eeuwen heen van Nederlanders hebben gehad. Hij stelt echter vast dat het gevaarlijk is om een essentialistische visie op de Nederlandse identiteit te hanteren omdat de stereotypen vaak gebaseerd zijn op reisverslagen van buitenlanders en door de tijd heen kunnen die stereotypen de beelden sterk beïnvloeden (www 1):

Over het algemeen wordt er gesproken van drie 'dominanten' die de stempel op de Nederlandse cultuur hebben gedrukt: het calvinisme, het landschap en handel. Deze drie zouden de Nederlandse cultuur typeren: de vastberaden oriëntatie van de predikant op godsdienstige leerstellingen, het vlakke land met zijn rechte lijnen en zijn duidelijke eenvoudige vormen en op de materiële gerichte koopmansgeest (www $1)$.

De meeste sociologen zijn van mening dat nationale identiteiten sociale constructen zijn. Daarom worden die benaderd als fluïde, altijd veranderlijke en heterogene sociale begrippen die een belangrijke rol spelen in de manier waarop mensen met elkaar omgaan en waarin landen en naties tegenover elkaar staan.

\section{Stereotypering en het beeld van Nederland}

Bij confrontaties met andere culturen zijn stereotyperingen onvermijdelijk. De stereotypen bepalen de eerste verwachtingen en de eerste waarnemingen, maar ze hangen altijd af van de culturele achtergrond van de waarnemer (Vossestein 1998: 21). In haar boek Effectief beeldvormen (1999) definieert Meijer beeldvorming als een mentaal proces waarbij stereotypen een belangrijke rol spelen. Volgens haar komen stereotypen tot stand door generaliseringen en geven ze een vaste en onveranderlijke vorm aan ideeën en beelden. Op die manier worden mentale beelden en voorstellingen onomstotelijke denkbeelden (Buikema, Meijer \& Smelik 1999: 24-25). Hoewel stereotypen vaker als negatief worden beschouwd, kan de positieve veralgemening ook 
als positief stereotype beschouwd worden (Macrae, Stangor \& Hewstone 1996: 14). In het artikel van Jelica Novaković-Lopušina wordt voor de eerste keer een systematisch overzicht gegeven van de stereotypering en beeldvorming over Nederland en Nederlanders in de Servische reisverhalen. In haar artikel De Nederlanden bekeken door de Servische reisbril (2013) analyseert de auteur zowel de eerste reisimpressies uit het interbellum als de reisverhalen die geschreven zijn in de communistische periode van na de WOII en tijdens de jaren negentig van de vorige eeuw. In alle door haar behandelde teksten komen vooral de verschillen met de Serviche cultuur en mentaliteit aan bod, waarbij de journalisten en schrijvers uit het laatste decennium van de twintigste eeuw de waarnemingen van de eerste reizigers vooral bevestigen terwijl zij ook bepaalde parallellen trekken tussen de bruisende leefstijl in Belgrado en Amsterdam (Novaković-Lopušina 2013: 278-279).

De bundel die hier nader besproken zal worden Hoe kan je de zon kopen? bestaat uit verschillende reisverhalen en artikels die zijn ontstaan in de periode 19701990. In die tijd werden ze gepubliceerd in verschillende Servische dagbladen en in 1992 werden ze gebundeld. De auteur beschrijft verscheidene Europese landen, steden, feestdagen en gewoontes en daardoor treedt hij op als bemiddelaar bij de beeldvorming over andere culturen. Er zijn twee reisverhalen over Nederland daarin te vinden, in het reisverhaal met de titel Waar de mens kleiner en groter wordt schrijft Nešić over zijn bezoek aan Den Haag en Madurodam en in De schoonmaakdag over Amsterdam en de viering van Koninginnedag.

\section{De Ander en het beeld van Nederlanders}

Elke bevolking, etnische groep of cultuur heeft zowel een bepaald zelfbeeld als een beeld van de ander. Het beeld van de ander wordt meestal gedefinieerd als "het omgekeerd spiegelbeeld van het zelf", als "een projectiefiguur", een soort "dumpplaats van datgene wat het subject in zichzelf afwijst" (Meijer 1996: 170). Volgens Van Alphen kan de eigen identiteit alleen geconstrueerd worden via een onderscheid met de ander zodat de constructie van de ander altijd een soort zelfreflectie impliceert. Bij het constructieproces van het zelf speelt de alteriteit of het anderszijn dus een beslissende rol (Van Alphen 1991: 1-15).

Het vaststellen van de meeste nationale identiteiten is te herleiden naar de $19 \mathrm{e}$ eeuw en het ontstaan van nationale staten. Het concept van de natiestaat en haar bevolking werd toen al gekenmerkt door één taal, cultuur, munteenheid, rechtssysteem, centraal gezag en het liefst één godsdienst (Obdeijn \& Schrover 2008: 54). Deze opvatting gaat gepaard met een monistisch mens- en wereldbeeld en werkt de overtuiging in de hand dat elke persoon alleen maar één vaste identiteit kan hebben (Hoffer 2012: 214). De Nederlandse identiteit heeft zich ook op die manier gevormd:

Tot voor kort was de Nederlandse identiteit weinig expliciet, maar toch was er een impliciete, onuitgesproken notie - van gedragscode en uiterlijk - aanwezig over wie wel of niet een "echte" Nederlander 
was. De Nederlandse burger heeft een lichaam en een religie, ofwel is wit met een joods/christelijke achtergrond (Hoffer 2012: 214, zoals geciteerd in Ghorashi (2006) Ruimte voor diversiteit).

\section{Nederlandse handelsgeest als prototype van de positieve stereotypering}

Nationale geschiedenis en identiteit zijn heel nauw met elkaar verbonden. In de periode tussen 1550 en 1650 begon het Nederlandse natiegevoel te bloeien omdat toen de onafhankelijke Nederlandse republiek werd gesticht. Die gevoelens hebben hun weerslag gevonden in de toenmalige literatuur.

In het toneelstuk van Vondel, Leeuwendalers (1648), zijn bijvoorbeeld al enkele stereotypen terug te vinden die de toenmalige Republiek der Verenigde Nederlanden als een ideaal land, met mooie natuur presenteren waar vooral welvaart, handel en tolerantie heersen. Dat ideaalbeeld had dus een belangrijke functie bij de totstandkoming van de soevereine staat na de Vrede van Munster in 1648. De protestantse ethiek speelde in de Gouden eeuw ook een belangrijke rol. Volgens het protestantse, calvinistische waardesysteem wordt het als moreel goed beschouwd om hard te werken en te sparen maar niet te genieten van het verdiende geld en het te verspillen op onnodige luxe. Dat arbeidsethos is sindsdien een dominant aspect geworden van de manier waarop Nederlanders handel drijven en waardoor ze zich in de loop van de tijd tot een befaamde handelsnatie hebben geprofileerd.

\section{Positieve stereotypering over Nederlanders}

In de tekst die over Madurodam gaat, hebben wij te maken met een tamelijk positieve stereotypering aangezien Nešić de beschrijvingen van Madurodam koppelt aan de beroemde en gewaardeerde eigenschappen die als typisch Nederlands worden beschouwd zoals soberheid, nuchterheid, efficiëntie en matigheid:

In Madurodam is ook de juiste maat gevonden: niets is er in disharmonie met de gedachten en gevoelens die opgeroepen dienen te worden, niets is er zoetsappig zoals dat onnodige versieringen zijn, niets is er afschrikwekkend, maar het is ook geen onnozel kinderspelletje (Nešić 1992: 46).

De Nederlandse socioloog P. Scheepers noemt in zijn onderzoek Maatschappelijke vooroordelen in perspectief (1995) de volgende kenmerken als typerend voor Nederlanders (aangegeven door buitenlanders): netheid, ordelijkheid en fatsoen. Deze waarden zouden samenhangen met "de burgerlijke cultuur van ons land, waarin ook grote nadruk werd en wordt gelegd op het gezinsleven, hard werken en vooruit komen in het leven" (Scheepers 1995: 5). Door Madurodam als een prototype van de 
Nederlandse rationaliteit aan de lezer voor te stellen herhaalt Nešić de cultuurtekst die Nederlanders als een praktische en op orde gerichte natie bestempelt. Door zijn beschrijvingen worden de al bestaande positieve stereotypen in werking gezet om een bepaalde werkelijkheidsgehalte te scheppen. Om die reden is het beeld van Nederland in dit reisverhaal eenzijdig waardoor de ideologische betekenisgeving van de lezer niet kan worden doorbroken.

Nešić heeft ook de bekende Nederlandse koopmansgeest opgemerkt tijdens de viering van de nationale feestdag. Het feit dat ze behalve feestvieren ook hun oude spullen op die dag proberen te verkopen en allerlei goedkope voorwerpen te vinden op de rommelmarkt bewijst dat hun neigingen tot handel drijven en zuinigheid altijd aanwezig zijn:

Die indruk dat dit de schoonmaakdag is, wordt versterkt door [...] het feit dat Nederlanders alles op straat zetten wat ze niet meer nodig hebben [...] Ook hier krijgt echter die handelsgeest de overhand, waar Nederlanders de wereld mee hebben veroverd vier á vijf eeuwen geleden [...] Zelfs degenen die eigen spullen hebben achtergelaten, gaan rond de verlaten stapels om in de kleren en huishoudelijke voorwerpen van anderen te snuffelen en daarin iets proberen te vinden wat voor iemand waardeloos is geworden maar voor hen misschien nog niet [...] (Nešić 1992: 81).

Door deze beschreven taferelen worden de cultuurteksten over Nederlanders als handelsnatie en zuinig volk nogmaals bevestigd.

\section{Ondermijning van de gevestigde beeldvorming}

In zijn reisverhalen ervaart Nešić andere volkeren en beschrijft hij ze vanuit de eigen Slavische achtergrond. Daardoor is de invalshoek waaruit die andere volkeren worden benaderd die van de ander. Nešić gebruikt in zijn tweede reisverhaal over Nederland, De schoonmaakdag, het vieren van de nationale feestdag, als de mogelijkheid om een ander gedragspatroon van Nederlanders te laten zien dat anders moeilijk zichtbaar is:

Als je je in Amsterdam bevindt op de laatste dag van april, zal alle kennis die je door het lezen hebt verworven over 'het land van tulpen' en de mensen die daar wonen op een onbetrouwbare en vergankelijke zeepbel lijken [...] (Nešić 1992: 79).

Door de beschrijvingen van het gedrag van Nederlanders op Koninginnedag ondermijnt de auteur de cultuurtekst over de Nederlandse mentaliteit en de eigenschappen die daarmee gepaard gaan zoals nuchterheid, gematigdheid en verstandigheid. Hij laat zien dat die mensen zich ook op een tegengestelde manier kunnen gedragen en dat losbandigheid, onstuimigheid, hartstochtelijkheid en driftigheid de hoogtij vieren: 
[...] is dat de dag, naar men beweert, wanneer de Nederlander zijn ware natuur laat zien en wordt wie hij/zij eigenlijk is - die tomeloze dolende Nederlander, dronken, onrustig, een onbevredigde losbol, zoals op de schilderijen van Rembrandt valt te zien, en niet alleen Germaans deftig en een spreekwoordelijk hardwerkende mier met een horizont die afgegrensd wordt door zijn inkomen en zijn huisdrempel (Nešić 1992: 79).

De taferelen die hij in de straten van Amsterdam ziet tijdens de festiviteiten vergelijkt Nešić met de voorstellingen op het beroemde schilderij De tuin der lusten van Hieronymus Bosch. Hij krijgt de indruk dat die feestdag een bijzondere gelegenheid is voor Nederlanders om zich aan hun driften over te laten. De titel van dat reisverhaal, De schoonmaakdag, zou uit die reden ook symbolisch kunnen worden opgevat. De mensen die immers zeer beheerst, nuchter, bedaard en gedisciplineerd zijn, veroorloven het zich op die ene dag van het jaar om als de figuren op het schilderij van Bosch hun driften wellustig en losbandig te bevredigen:

Het lijkt alsof het schilderij van Hieronymus Bosch, De tuin der lusten, in beweging is gebracht, en je begint erin te geloven dat de dolle schilder niets heeft verzonnen, omdat zijn modellen herleefd zijn, losbandig en zondig, grappig en droevig in een onuitlegbare moeite om tijdens die ene dag alle woede uit zichzelf te verdrijven, alles wat in hen nog schuilt en wat niet door de beschaving getoomd is [...] zodat ze morgen, gezuiverd en opgelucht, naar het betreden pad van het alledaagse leven zouden kunnen terugkeren (Nešić 1992: 81).

In dezelfde tekst wordt tevens de nadruk gelegd op de bekende dichotomie tussen Germaans en Slavisch waardoor een aantal stereotype voorstellingen weer worden herhaald. Tegenover de Germaanse koudbloedigheid, terughoudendheid en bescheidenheid staan de Slavische vurigheid, hartelijkheid, overmatigheid en de bohémien leefstijl:

Nederlanders, die trouwens het grootste deel van hun leven in hun huizen doorbrengen, gaan allemaal naar buiten en het is alsof de pantsers van de koude noorderlingen barsten vertonen waardoor uit de koude noorderlingen, zoals wij ze meenden te kennen ineens de meest vurige zuiderlingen naar voren treden. Er ontstaat een luidruchtig gedrang en een wervelende menigte als op Servische kermissen en dorpsfeesten (Nešić 1992: 80).

\section{Conclusie}

De beeldvorming die in de reisverhalen van Nešić tot stand komt, is grotendeels gebaseerd op al bestaande stereotypen en generaliseringen over Nederland en 
haar inwoners. De dominante, vooral positieve, stereotypering over Nederland en Nederlanders wordt in het eerste reisverhaal gestaafd door te laten zien dat de rationaliteit en efficiëntie daar zelfs in de ruimte en architectuur worden weerspiegeld. In het tweede reisverhaal worden stereotiepe voorstellingen enigszins ondergraven omdat er een tegengesteld gedragspatroon wordt gepresenteerd dat in het algemeen verborgen blijft en zich alleen maar in bijzondere situaties manifesteert. Op die manier wordt er de keerzijde getoond van de Nederlandse mentaliteit.

De ideologie waarvan de auteur, hier dus ook de bemiddelaar tussen twee culturen, uitgaat, vestigt enerzijds al bestaande stereotypen maar geeft anderzijds toch andere (subjectieve) inzichten weer. Zijn werkelijkheidsweergave is in hoge mate gebaseerd op de dichotomie tussen de Slavische en Germaanse identiteit en op de voorkennis die gekoppeld is aan de protestantse ethiek. De representaties van de Nederlanders in deze teksten werken de ideologische betekenisgeving bij het leesproces gedeeltelijk tegen aangezien er bepaalde cultuurteksten over Nederlanders gedeconstrueerd worden.

\section{Literatuuropgave}

Alphen, van E. red. R. Corbey, \& J. Leerssen.1991. The Other Within. Alterity, Identity, Image. Selves and Others in Society and Scholarship. Amsterdam/Atlanta: Rodopi.

Hoffer, C. 2012. 'Identificatie: een dynamische benadering van identiteitsvorming'. Interculturele Jeugd-en Opvoedhulp. Een cultureel venster op de hulpverlening aan migrantenjongeren en hun gezinnen. Delft: Eburon, pp. 115-120.

Macrae, C. N., Stangor, C., \& Hewstone, M. 1996. Stereotypes and Stereotyping. New York / London: Guilford Press.

Meijer, M. 1996. In tekst gevat. Inleiding tot een kritiek van representatie. Amsterdam: University Press.

Nešić, T. 1992. Kako kupiti sunce? Niš: Prosveta

Novaković-Lopušina, J. 2013. 'De Nederlanden bekeken door de Servische reisbril'. In: Heuckelom, Kris Van; Dieter De Bruyn \& Carl De Strycker (red.): Van Eeden tot heden. Literaire dwarsverbanden tussen Midden-Europa en de Lage Landen. Gent: Academia Press, pp. 257-279.

Obdeijn, H \& Schrover, M. 2008. Komen en gaan. Immigratie en emigratie in Nederland vanaf 1550. Amsterdam: Bert Bakker.

Smelik, A. met Buikema R., \& Meijer, M. 1999. Effectief beeldvormen: theorie, analyse en praktijk van beeldvormingsprocessen. Assen: Van Gorcum.

Vossestein, J. 1998. Zo werkt dat in Nederland. Amsterdam: Stichting Lm Publishers. 


\section{Internetbronnen}

Www 1

Fesunenko, M. 2010. Een onderzoek naar de betekenis en primaire socialisatie van de Nederlandse nationale identiteit en de ervaren etnische dreiging. Geraadpleegd op 18 februari 2018 van https://dspace.library.uu.nl/bitstream/handle/1874/187049/ Masterthesis\%20Fesunenko.pdf? sequence $=1$

www 2

Zwart, van der W. 2007. Identiteitsvorming in een veranderende samenleving. Geraadpleegd op 20 februari 2018 van http:/gpm.ruhosting.nl/ mt/2008MASG28ZwartWendyvander.pdf 